\title{
Fabrication and Characterization of MEMS Based Optical Hydrogen Sensors
}

\author{
Hwan-Gil Hwang, Kang-San Kim, Gwiy-Sang Chung* \\ School of electrical engineering, University of Ulsan, Republic of Korea \\ *gschung@ulsan.ac.kr
}

\begin{abstract}
This paper presents the fabrication and characterization of MEMS based optical type hydrogen sensors using transparent 3C-SiC membrane and photovoltaic effect. 3C-SiC membrane was fabricated by anisotropic etching. Gasochromic material of Pd was deposited by sputter on the 3C-SiC membrane for gas sensing layer. $\mathrm{Pd}$ and $\mathrm{WO}_{3}$ changes to transparency by exposure to hydrogen and the variations of light intensity generate the photovoltaic of $\mathrm{P}-\mathrm{N}$ junction between N-type $3 \mathrm{C}-\mathrm{SiC}$ and P-type Si. Photovoltaic increased with increase of hydrogen concentration. $\mathrm{Pd} / \mathrm{WO}_{3}$ shows almost 2 times faster response and recovery toward hydrogen compared with $\mathrm{Pd}$. However, low response factor is shown at $\mathrm{Pd} / \mathrm{WO}_{3}$ by low penetration ratio.
\end{abstract}

Key words: Optical type hydrogen sensor, $3 \mathrm{C}-\mathrm{SiC}$ thin film, Photovoltaic, $\mathrm{Pd}, \mathrm{WO}_{3}$

\section{Introduction}

Due to the energy crisis related to the limited resources of fossil fuels, hydrogen is considered the most attractive energy resources in the future for its high efficiency, renewability, and the fact that it is environmentally friendly [1]. Hydrogen is currently used as a fuel for internal-combustion engines and fuel cells, which may soon become ubiquitous in automobiles and homes due to the potential for substantially cleaner emissions when compared to industrial combustion engines [2]. However, general hydrogen sensors such as catalytic, electrochemical and semiconductor sensors use electrical leads, which may induce sparks and provide a cause for ignition in hazardous atmospheres. Therefore, optical type hydrogen sensors based on fiber optics allow working in an explosive environment thanks to the possibility of separating the sensing point from the electrical readout [3]. Various strategies have been proposed, which basically infer the hydrogen concentration from a change in the optical response e.g. the interference pattern, the frequency of the optical signal, or in the intensity of the optical signal. However, optical signal measurement system is expensive and huge. So, portability is restricted. Moreover, low mechanical strength of optical fiber is limiting the portable sensor application. $3 \mathrm{C}-\mathrm{SiC}$ is interesting material for two third generation photovoltaic (PV) material [4]. Recently, photocapacitance properties of $3 \mathrm{C}-\mathrm{SiC} / \mathrm{p}-\mathrm{Si}$ structure were studied [5]. These properties can be utilized as light detecting parts. Changes of voltage can be achieved from variations of light intensity according to hydrogen concentration. Also, chemical stability and transparent of 3CSiC membrane can be replace the optical fiber which exposure to humidity and hydrogen make color change and crack by decomposition $\left(\mathrm{SiO}_{2}+\mathrm{H}_{2} \mathrm{O}->\mathrm{Si}-\mathrm{O}-\mathrm{HH}-\mathrm{O}-\mathrm{Si}\right)$.

In this work, chemically stable 3C-SiC membrane and 3C-SiC/P-Si structures were used optical type hydrogen sensor as sensing part and detection part, respectively. After integrate the light source with sensing part, hydrogen sensing characteristics are evaluated with the hydrogen concentration of $2 \sim 10 \%$.

\section{Experimental}

Two kinds of 3C-SiC on substrates are employed for fabrication of sensing and detection parts, respectively. $2 \mu \mathrm{m} 3 \mathrm{C}$-SiC thin film deposited on the oxide wafer was used for sensing part. 3C-SiC membrane fabricated by photolithography and back side anisotropic etching in $\mathrm{TMAH}\left(\mathrm{CH}_{3}\right)_{4} \mathrm{NOH}$ for 16 hours. Gasochromic materials of $\mathrm{Pd}$ and $\mathrm{Pd} / \mathrm{WO}_{3}$ deposited on 3C-SiC membrane by sputtering. $\mathrm{Pd}$ and $\mathrm{WO}_{3}$ were deposited $20 \mathrm{sec}$ with $100 \mathrm{~W}$ and $60 \mathrm{sec}$ with $50 \mathrm{~W}$, respectively. After deposition of catalysts, 3C-SiC membrane integrated with LED light source. $0.3 \mu \mathrm{m} 3 \mathrm{C}$-SiC thin films on P-type Si were used as detection 
part. For measure of photovoltaic effect at 3C$\mathrm{SiC}$ and P-type Si, $\mathrm{Al}$ electrodes were deposited the surface of $3 \mathrm{C}-\mathrm{SiC}$ and back side of Si. $100 \%$ hydrogen mixed with $\mathrm{N}_{2}$. Net hydrogen concentrations range was from $2 \sim 10 \%$. Hydrogen sensing properties are analyzed in dark chamber. Fig. 1 shows the schematic diagram of light source integrated with sensing part and measurement system.

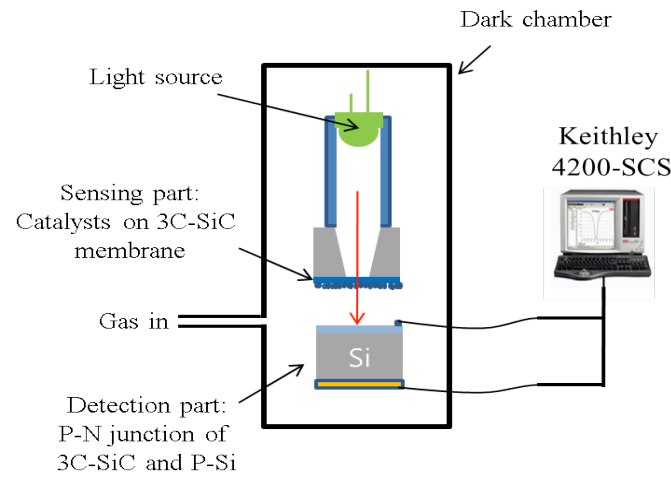

Fig. 1. Schematic diagram of MEMS based optical type hydrogen sensors and their measurement system.

\section{Results and discussion}

One cycle response with catalysts and hydrogen concentration are shown in Fig. 2 (a) $\mathrm{Pd}$ and (b) $\mathrm{Pd} / \mathrm{WO}_{3}$, respectively.

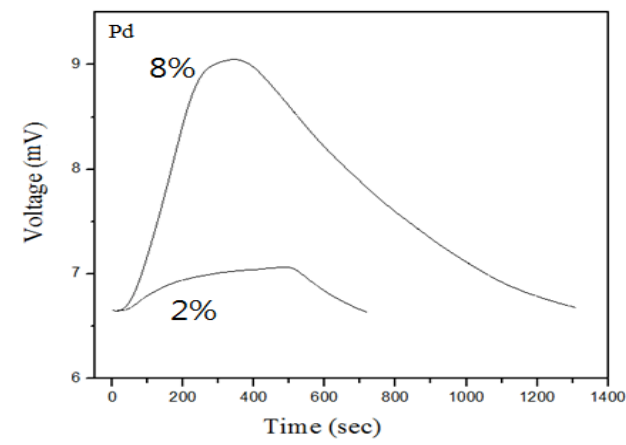

(a)

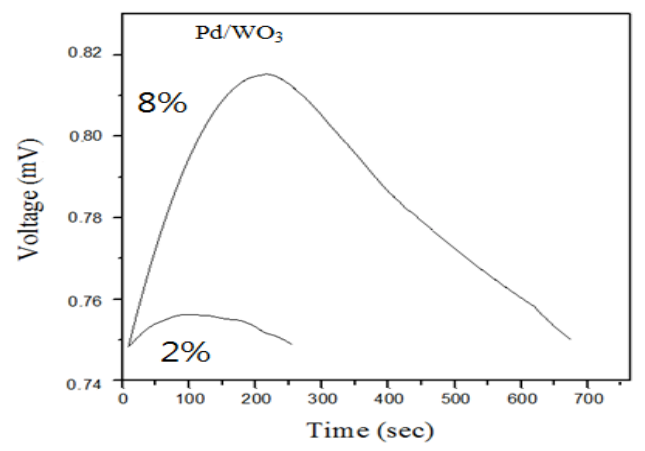

(b)

Fig. 2. Responses of the sensors toward different $\mathrm{H}_{2}$ concentrations at room temperature: (a) $\mathrm{Pd}$ and (b) $\mathrm{Pt} / \mathrm{WO}_{3}$.
Gas chromic materials of $\mathrm{Pd}$ and $\mathrm{WO}_{3}$ are changed to transparency when exposure to hydrogen. Thus, generated voltage from P-N junction of $3 \mathrm{C}$-SiC and $\mathrm{Si}$ increased with hydrogen on and decreased hydrogen off. $\mathrm{Pd} / \mathrm{WO}_{3}$ shows low photovoltaic compared with $\mathrm{Pd}$ only. These come from two layer of $\mathrm{Pd} / \mathrm{WO}_{3}$ makes low penetration ratio. There is almost no baseline shift in the sensor signal.

Fig. 3 shows the photovoltaic variations of optical hydrogen sensors coated with (a) Pd and (b) $\mathrm{Pd} / \mathrm{WO}_{3}$ according to hydrogen concentration. In case of $\mathrm{Pd}$, over than $6 \%$ hydrogen concentration, variation of output voltage is decreased compared with $2 \sim 4 \%$. However, $\mathrm{Pd} / \mathrm{WO}_{3}$ shows linear response with hydrogen concentrations. These come from phase transition. Phase transition from $\alpha$ to $\beta$ is shown after $6 \%$ in Fig. 3 (a) [6]. However, Pd catalyst increased reaction of $\mathrm{WO}_{3}$ with hydrogen in Fig. 3 (b) [7].

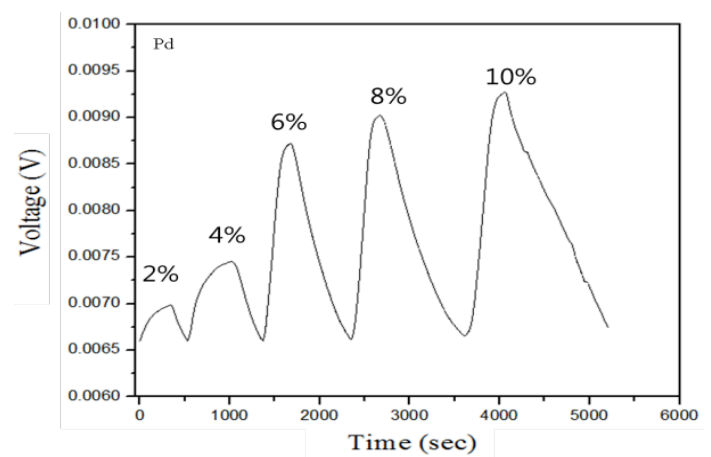

(a)

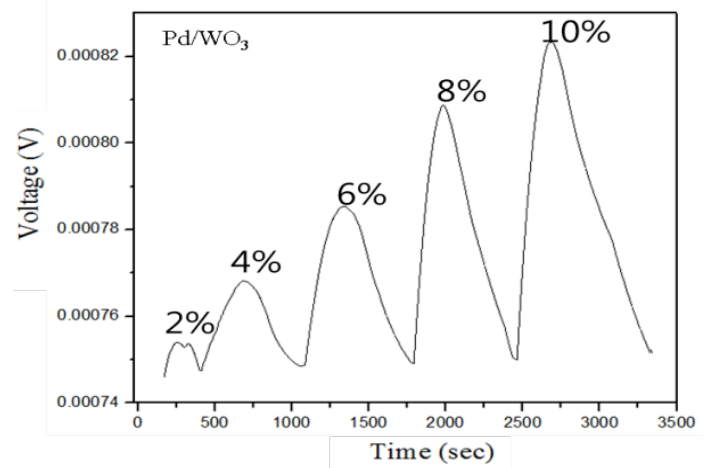

(b)

Fig. 3. Photovoltaic variations of optical hydrogen sensors coated with (a) $\mathrm{Pd}$ and (b) $\mathrm{Pd} / \mathrm{WO}_{3}$ according to hydrogen concentration.

Fig. 4 (a) and (b) shows response time (time to reach $90 \%$ of the maximum transition value) and the recovery time (time to reach $90 \%$ of the initial value) of $\mathrm{Pd}$ and $\mathrm{Pd} / \mathrm{WO}_{3}$, respectively. Response and recovery time increased with increase of hydrogen concentrations. At $10 \%$ hydrogen concentration, response and recovery time of $\mathrm{Pd}$ was $300,900 \mathrm{sec}$ and $\mathrm{Pd} / \mathrm{WO}_{3}$ was 180, $500 \mathrm{sec}$, respectively. 


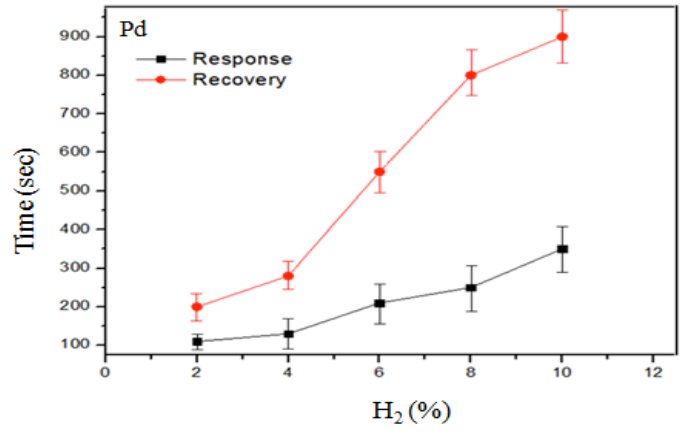

(a)

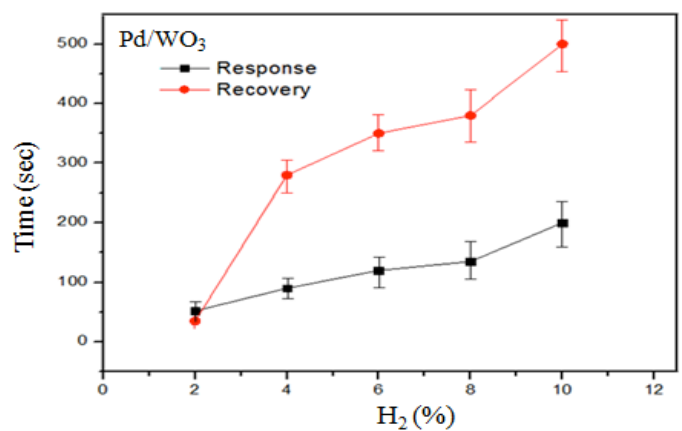

(b)

Fig. 4. Response and recovery time of $\mathrm{Pd}$ and $\mathrm{Pd} / \mathrm{WO}_{3}$ with hydrogen concentration.

Tab. 1 shows response factors of $\mathrm{Pd}$ and $\mathrm{Pd} / \mathrm{WO}_{3}$, respectively. The response factor can be considered as an indirect measurement of the device sensor signal. The response factor was calculated as follows:

$$
\text { Response factor }(\%)=\left(\frac{V_{\text {initial }}-V_{\text {response }}}{V_{\text {initial }}}\right) \cdot 100
$$

where $V_{\text {initial }}$ is the voltage measured in air and $V_{\text {response }}$ is the voltage at each hydrogen concentrations. Response factor increased with the increase of hydrogen concentrations. However, $\mathrm{Pd} / \mathrm{WO}_{3}$ structure shows low response factors by low penetration ratio. If thickness of $\mathrm{Pd} / \mathrm{WO}_{3}$ will optimize, out signal of photovoltaic should be improve.

\section{Conclusions}

In this work, optical type hydrogen sensors using 3C-SiC membrane and photovoltaic were fabricated and evaluated. 3C-SiC membrane was integrated with LED light source and P-N junction of $\mathrm{SiC} / \mathrm{Si}$ was used as a detection parts. $\mathrm{Pd}$ and $\mathrm{Pd} / \mathrm{WO}_{3}$ were used as sensing materials and detected hydrogen range from $2 \sim 10 \%$. In case of $\mathrm{Pd}$, output signal decreased at high concentration of hydrogen by phase transition. $\mathrm{Pd} / \mathrm{WO}_{3}$ shows linear response signal with hydrogen concentrations. However, $\mathrm{Pd} / \mathrm{WO}_{3}$ structure shows low response factors compared with $\mathrm{Pd}$. This means the $\mathrm{Pd} / \mathrm{WO}_{3}$ has
Tab. 1: Variation of response factor (\%) with hydrogen concentration.

\begin{tabular}{|c|c|c|}
\hline $\mathrm{H}_{2}(\%)$ & $\mathrm{Pd}$ & $\mathrm{Pd} / \mathrm{WO}_{3}$ \\
\hline 2 & 7.69 & 1.33 \\
\hline 4 & 12.30 & 4 \\
\hline 6 & 34.61 & 5.33 \\
\hline 8 & 38.46 & 7.33 \\
\hline 10 & 42.3 & 10 \\
\hline
\end{tabular}

more low penetration ratio compared with $\mathrm{Pd}$. If thickness of $\mathrm{Pd} / \mathrm{WO}_{3}$ will optimize, out signal of photovoltaic should be improve. Novel optical type hydrogen sensor based on 3C-SiC membrane and photovoltaic effect can be applied to high concentration of hydrogen and VOC sensors.

\section{Acknowledgement}

This research was supported by the Korea Research Foundation Grant through the Human Resource Training Project for Regional Innovation funded by 2011 the Korean Government which was conducted by the Ministry of Education, Science and Technology.

\section{References}

[1] N. Taşaltın, S. Öztürk, N. Kılınç, Z. Z. Öztürk, Temperature dependence of a nanoporous $\mathrm{Pd}$ film hydrogen sensor based on an AAO template on Si, Applied Physics A 97, 745-750 (2009); doi: 10.1007/s00339-009-5440-7

[2] O. Lupan, G. Chai, L. Chow, Novel hydrogen gas sensor based on single $\mathrm{ZnO}$ nanorod, Microelectronic Engineering 85, 2220-2225 (2008); doi: 10.1016/j.mee.2008.06.021

[3] V. Palmisano, M. Filippi, A. Baldi, M. Salman, H. Schreuders, B. Dam, An optical hydrogen sensor based on a Pd-capped $\mathrm{Mg}$ thin film wedge, International Journal of Hydrogen Energy 35, 12574-12578 (2010); doi: 10.1016/j.ijhydene. 2010.09.001

[4] B. S. Richards, A. Lambertz, R. P. Corkish, C. A. Zorman, M. Merhregany, M. Ionescu, M. A. Green, 3C-SiC as a future photovoltaic material, 3rd World Conference on Photovoltaic Energy Conversion 3, 2738-2741 (2003)

[5] K.S. Kim, R.K. Gupta, G.S. Chung, F. Yakuphanoglu, Effects of illumination on capacitance characteristics of $\mathrm{Au} / 3 \mathrm{C}-\mathrm{SiC} / \mathrm{p}-\mathrm{Si} / \mathrm{Al}$ diode, Journal of Alloys and Compounds 509, 10007-10013 (2011); doi: 10.1016/j.jallcom.2011 08.012

[6] M. Zhao, J.X. Huang, M.H. Wong, Y.M. Tang, C.W. Ong, Versatile computer-controlled system for characterization of gas sensing materials, Review of Scientific Instruments, 105001(1)105001(6) (2011); doi: 10.1063/1.3648132

[7] M. Yang, Y. Sun, D. Zhang, D. Jiang, Using $\mathrm{Pd} / \mathrm{WO} 3$ composite thin films as sensing materials for optical fiber hydrogen sensors, Sensors and Actuators B: Chemical, 750-753 (2010); doi: 10.1016/j.snb.2009.10.017 